\title{
Flora of Eroded Hillsides
}

\section{by Keith F. Best, Swift Current}

Each year during the month of May many of our dry hillsides and eroded areas burst forth with a deep blue floral display. A hairless perennial of the Figwort family, the Smooth Blue Beard-tongue (Penstemon nitidus has a stout $\mathbf{s}^{1} \mathrm{em}$ which often branches from the crown and grows from 8 to 12 inches in height. The leaves are opposite, the lower ones lanceolate to oblanceolate 1 to 2 inches long, while the upper leaves. are more ovate in shape and smaller in size. The dense, leafy racemes of flowers are generally a deep blue although variations ranging from purple through red to white do occur. The flowers have a funnel shape, widening towards the throat. There are five stamens (one of which is sterile), giving rise to the generic name. The fruit is an ovoid, manyseeded capsule. Although generally weak seeders, the Penstemons have strong root 'systems and reproduce rather vigorously by means of rootstocks. Many of the Penstemons are very attractive and are grown as ornamentals.

\section{SMOOTH BLUE}

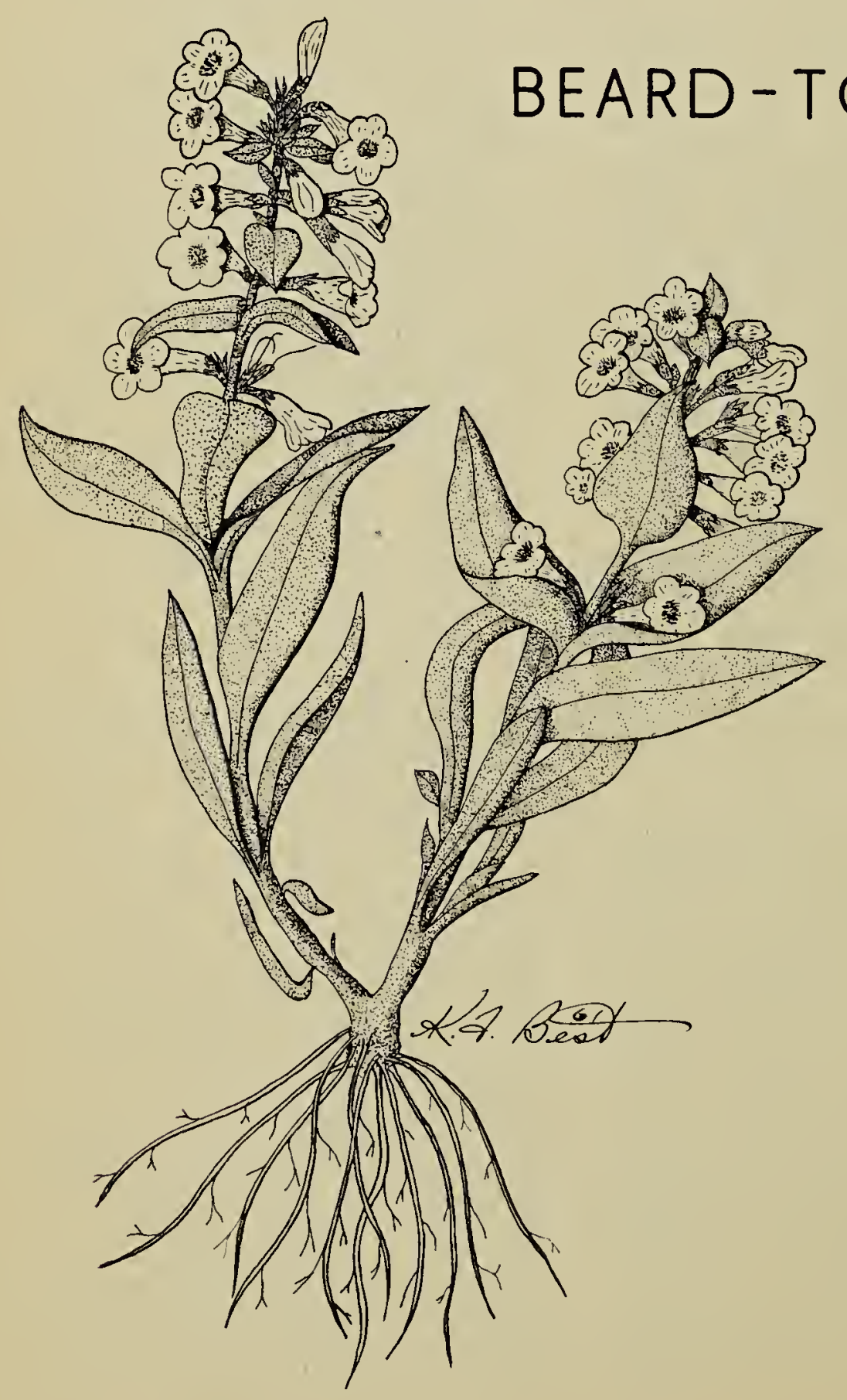




\section{YELLOW UMBRELLA PLANT}

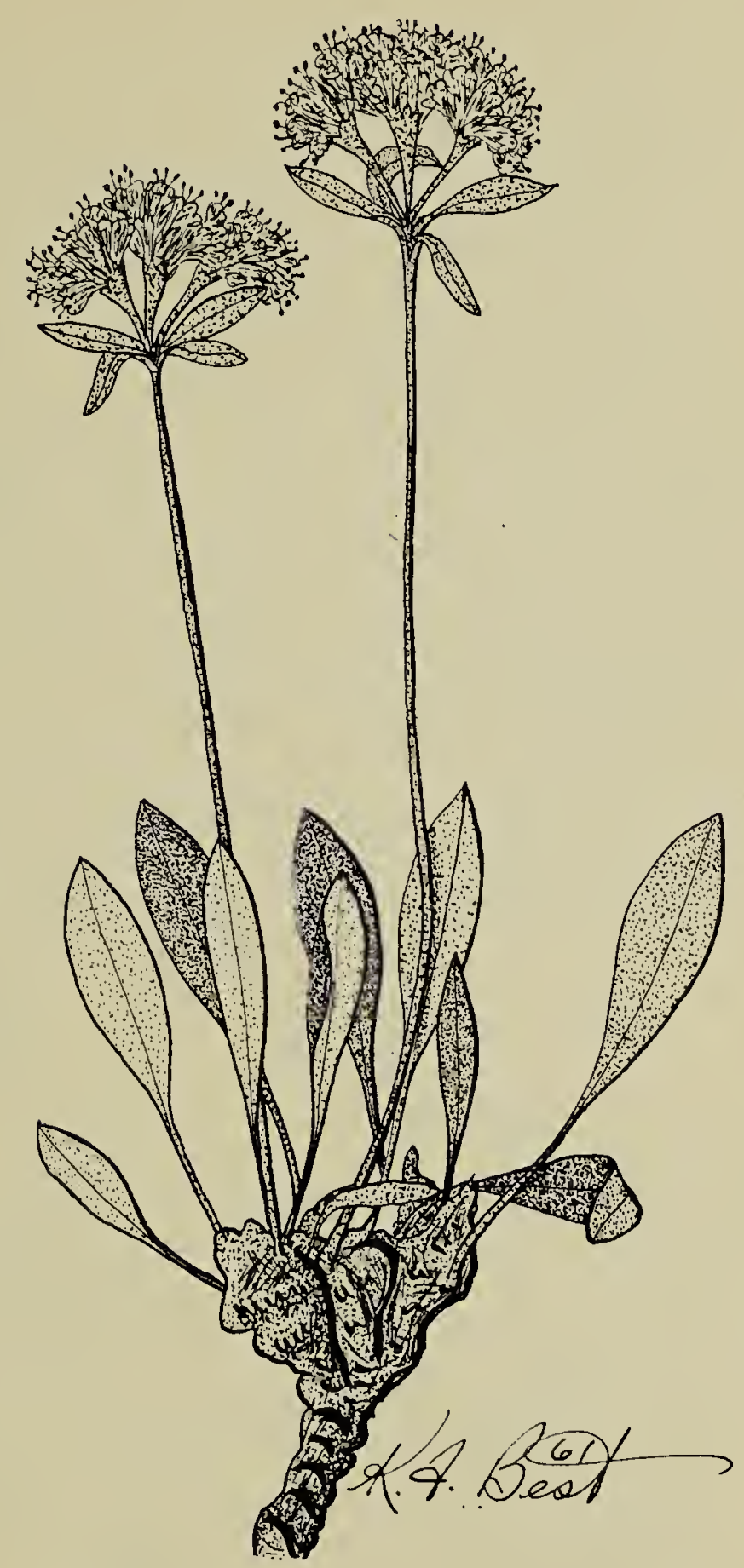

Another species commonly found on these eroded areas that have lost the best of their surface soil is the Yellow Umbrella Plant (Eriogonum flavum), a low growing perennial of the Buckwheat family. This species grows from a coarse, tufted woody root. The leaves, from $1 \frac{1 / 4}{4}$ to 2 inches long, all come from the base, and are usually linear-oblong or spatulate in shape. The leaves are green, the under surface being densely white woolly while the upper portions are only slightly hairy.
The flowers are in small umbrellalike clusters at the head of stems and are pale yellow in color. The individual flowers are small and although they have no petals, the sepals are coloured, more or less united, and persist around the single, usually three - angled, one - seeded achene. There is a whorl of bracts below the flower clusters. Flowering generally occurs near the middle of June. 
Vol. XX, No. 1

\section{The Bur Oak}

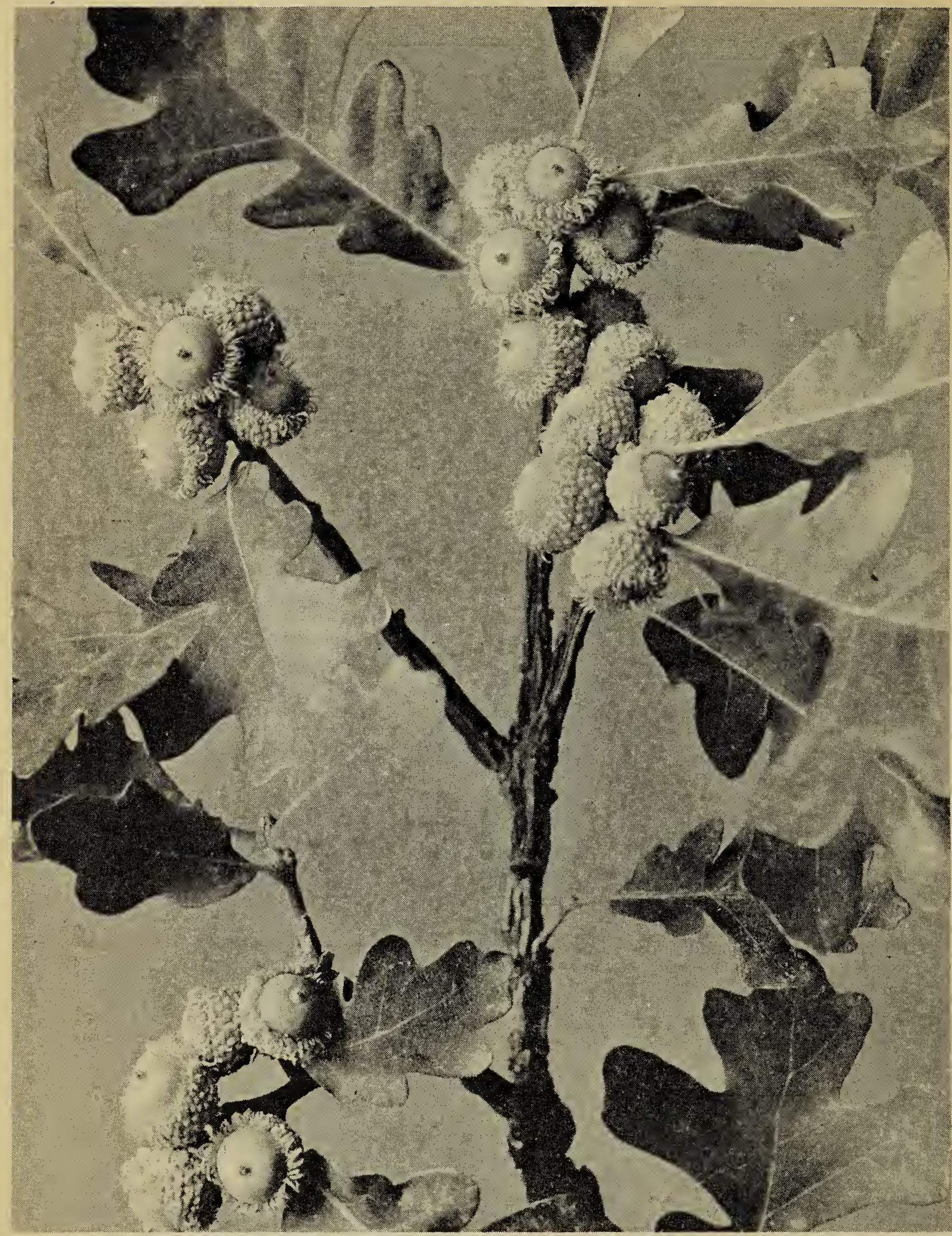

Quercus macrocorpa Mlchx.

Photo by W. C. McCollo

The Bur Oak or Mossycup Oak is a large tree in eastern Conoda but it is reduced to a shrub in the western limit of its range. The Bur Oak extends westward into eastern Saskatchewan along the Pipestone and Qu'Appelle Valleys. It is not recorded for Alberta. The oicture above is taken at about $3 / 5$ notural size. The trees shown in the other picture were $14-16$ inches in diameter at breast height. 